\title{
The Role of Pannexin3-Modified Human Dental Pulp-Derived Mesenchymal Stromal Cells in Repairing Rat Cranial Critical-Sized Bone Defects
}

\author{
Fangfang Song $^{\mathrm{a}}$ Hualing Sun ${ }^{\mathrm{a}}$ Liyuan Huang ${ }^{\mathrm{a}}$ Dongjie Fu ${ }^{\mathrm{b}}$ Cui Huang ${ }^{\mathrm{a}}$ \\ aThe State Key Laboratory Breeding Base of Basic Science of Stomatology (Hubei-MOST) \& Key \\ Laboratory of Oral Biomedicine Ministry of Education (KLOBM), School \& Hospital of Stomatology, \\ Wuhan University, Wuhan, Hubei, ${ }^{\mathrm{b}}$ Department of Stomatology, Renmin Hospital of Wuhan University, \\ Wuhan, Hubei, China
}

\section{Key Words}

Pannexin3 - Human dental pulp-derived mesenchymal stromal cells $-W n t / \beta$-catenin - ERK • Critical-sized bone defect $\bullet$ Bone tissue engineering

\begin{abstract}
:
Background/Aims: Human dental pulp-derived mesenchymal stromal cells (hDPSCs) are promising seed cells for tissue engineering due to their easy accessibility and multilineage differentiation. Pannexin3 (Panx3) plays crucial roles during bone development and differentiation. The aim of the present study was to investigate the effect of Panx3 on osteogenesis of hDPSCs and the underlying mechanism. Methods: Utilizing qRT-PCR, Western blot, and immunohistochemistry, we explored the change of Panx3 during osteogenic differentiation of hDPSCs. Next, hDPSCs with loss (Panx3 knockdown) and gain (Panx3 overexpression) of Panx3 function were developed to investigate the effects of Panx3 on osteogenic differentiation of hDPSC and the underlying mechanism. Finally, a commercial $\beta$-TCP scaffold carrying Panx3-modified hDPSCs was utilized to evaluate bone defect repair. Results: Panx 3 was upregulated during osteogenic differentiation in a time-dependent manner. Panx3 overexpression promoted osteogenic differentiation of hDPSCs, whereas depletion of Panx3 resulted in a decline of differentiation, evidenced by upregulated expression of mineralization-related markers, increased alkaline phosphatase (ALP) activity, and enhanced ALP and Alizarin red staining. Panx3 was found to interact with the $W n t / \beta$-catenin signaling pathway, forming a negative feedback loop. However, Wnt/ $\beta$-catenin did not contribute to enhancement of osteogenic differentiation as observed in Panx3 overexpression. Moreover, Panx3 promoted osteogenic differentiation of hDPSCs via increasing ERK signaling pathway. Micro-CT and histological staining results showed that Panx3-modified hDPSCs significantly improved ossification of critical-sized bone defects. Conclusion: These findings suggest that Panx3 is a crucial modulator of hDPSCs differentiation.




\section{Cellular Physiology Cell Physiol Biochem 2017;44:2174-2188 \\ \begin{tabular}{l|l|l} 
and Biochemistry Published onlIne: December 13, 2017 & $\begin{array}{l}\text { (c) } 2017 \text { The Author(s). Published by S. Karger AG, Basel } \\
\text { www.karger.com/cpb }\end{array}$ \\
\hline
\end{tabular}}

Song et al.: Panx3 Promotes Osteogenesis of Hdpscs in Vitro and in Vivo

\section{Introduction}

Critical-sized bone defect does not heal spontaneously and will be occupied by connective tissue. Therefore, treatment of such defects remains a great challenge to clinicians [1]. Autologous bone grafting is a well-established clinical procedure and is considered gold standard for bone defect repair. However, autografting is limited by bone availability, donor site morbidity and postoperative complications [2]. In recent years, bone tissue engineering has attracted more attention as a promising treatment for bone defect. Successful tissue engineering contains three factors: seed cells, biomaterials and bioactive molecules. Mesenchymal stem cells (MSCs) are an attractive cell type for tissue engineering due to their multi-lineage differentiation capabilities including osteoblast, adipocytes and chondrocytes $[3,4]$. Human dental pulp-derived mesenchymal stem cells (hDPSCs) are easily accessible from the permanent human dental pulp through a slightly uncomfortable procedure $[5,6]$. hDPSCs are derived from mesenchyme and neural crest, and thus possess several properties of MSCs $[5,7,8]$. In addition, these cells exhibit higher proliferative, mineralization, and immunoregulatory capacities compared with bone marrow-derived MSCs and maintain multi-lineage differentiation potentials even after long-term cryopreservation $[9,10]$. These characteristics render hDPSCs as suitable seed cells for cell-based therapeutics and tissue engineering $[11,12]$. Especially, hDPSCs have been demonstrated to be successfully employed as a promising therapeutic tool for bone defects repair [11,13,14].

The pannexin (Panx) family consists of three glycoproteins (Panx1, Panx2, and Panx3), which form hemichannels and facilitate the passage of ions and small molecules (such as calcium and ATP) from the intercellular space to the extracellular microenvironment [15]. Panx3 has been reported to promote osteogenic and chondrogenic differentiation in mice progenitor cells $[15,16]$. However, the expression tendency and role of Panx3 in primary hDPSCs during osteogenic differentiation is still unclear, and the expression pattern and mediatory effects of Panx3 might differ across various cells and species. For example, the expression profile and role of other factors such as miR-34a varies during osteogenic differentiation among different cells $[17,18]$. Clarifying the role and molecular mechanisms by which Panx3 controls osteogenic differentiation of hDPSCs and elucidating the boneforming ability of Panx3-modified hDPSCs in vivo will provide a more complete understanding of osteogenesis of hDPSCs and drive the application of gene therapy for bone repair through regulation of key factors.

In this study, we systematically investigated the effect of Panx3 on osteogenic differentiation of hDPSCs and the underlying mechanism by employing Panx3 loss- and gain-of function approaches. Furthermore, we explored the bone-forming ability of Panx3modified hDPSCs using a rat cranial critical-sized bone defect model. We anticipated that this model could be a meaningful paradigm for cell-based therapy of Panx3-modified hDPSCs.

\section{Materials and Methods:}

Plasmid construction

The plasmid constructs Wnt3a-pUSEamp, pUSEamp, TOPflash, FOPflash and pGL3-Basic were purchased from Millipore (Billerica, MA, USA). pGL3-Basic and pRL-TK were purchased from promega (Madison, WI, USA). shRNA targeting the human Panx3 gene named lenti-shRNA-Panx3 and human $\beta$-catenin were purchased from Genechem (Shanghai, China).

Putative Panx3 promoter fragment were cloned using genomic DNA as template according to the manufacture's instruction of Prime STAR Max DNA (Takara Bio Inc, Shiga, Japan). The primers were listed in Table1. The product was directionally cloned into Kpnl and Xhol restriction sites of pGL3-Basic, named Panx3-promoter (Fig. 4F).

The Panx3 overexpression plasmid was constructed according to previous study [19]. Briefly, the fulllength of Panx3 CDS was directionally cloned and inserted into pLVX-IRES-ZsGreen1, named lenti-Panx3.

pLVX-IRES-ZsGreen1 (lenti-Plvx) and a nonsense shRNA sequence exhibiting no homology to the Panx3 (lenti-shRNA-Ctrl) were employed as negative controls. 


\section{Cellular Physiology Cell Physiol Biochem 2017;44:2174-2188 \begin{tabular}{l|l|l} 
and Biochemistry Published online: December 13, 2017 & $\begin{array}{l}\text { (c) } 2017 \text { The Author(s). Published by S. Karger AG, Basel } \\
\text { www.karger.com/cpb }\end{array}$ \\
\hline
\end{tabular}}

Song et al.: Panx3 Promotes Osteogenesis of Hdpscs in Vitro and in Vivo

\section{Generation of Wnt3a-conditioned medium}

HEK293E were transfected using Lipofectamine 2000 (invitrogen, CA, USA) with the Wnt3a-pUSEamp to generate Wnt3a-conditioned medium. The pUSEamp was used as control. After transfection for $6 \mathrm{~h}$, the medium was discarded and replaced with fresh medium. After incubation for $48 \mathrm{~h}$, the culture supernatants were harvested, filtered using a $0.22 \mu \mathrm{m}$ filter, and designated as Wnt3a-conditioned medium and control.

\section{Cell culture and treatment of hDPSCs}

Healthy third molars and premolars were collected from 15-25-year-old patients with informed consents undergoing extraction at the School and Hospital of Stomatology, Wuhan University, which was approved by the Institutional Ethical Board of Wuhan University. The pulp tissues were immediately extracted, minced into pieces and digested with the mixture of $3 \mathrm{mg} / \mathrm{mL}$ collagenase I (Life Technologies Europe B.V., Zug ZG, Switzerland) and $4 \mathrm{mg} / \mathrm{ml}$ dispase (Roche Applied Science, Mannheim, Germany) for $1 \mathrm{~h}$ at $37^{\circ} \mathrm{C}$ on shaker to obtain single-cell suspensions [20]. Primary cells were cultured in $\alpha$-MEM (minimal essential medium, $\alpha$ modification) (Hyclone, Logan, UT, USA) containing 10\% fetal bovine serum (FBS) (Hyclone) and 1\% penicillin/streptomycin (P/S, Jinuo, Hangzhou, China) at $37^{\circ} \mathrm{C}$ in humidified atmosphere of $5 \% \mathrm{CO}_{2}$, and the medium was refreshed every 3 days. hDPSCs were passaged upon reaching 70-80\% confluence, and the cells at passage 3-5 were used for following studies. To induce osteogenic differentiation, the hDPSCs were induced using osteogenic induction medium (OM) (complete medium supplemented with $50 \mathrm{ug} / \mathrm{mL}$ l-ascorbic acid (Sigma-Aldrich), $10 \mathrm{mM} \beta$-glycerophosphate (Sigma-Aldrich), and $10 \mathrm{nM}$ dexamethasone (Sigma-Aldrich)). In particular experiments, hDPSCs were grown in the presence of indicated concentration of Wnt3a-conditioned medium $(0,10 \%, 20 \%, 40 \%$ and $80 \%)$ and $\mathrm{LiCl}(0 \mathrm{mM}$, $5 \mathrm{mM}, 10 \mathrm{mM}$ and $20 \mathrm{mM}$ ) for $24 \mathrm{~h}$.

\section{Lentivirus production and transduction}

Lentiviruses were produced through transfecting HEK293E with a three-plasmid system, including lentiviral vector, psPAX2, and pMD2.G, using Turbofect (Thermo, MA, USA) according to previous study [19]. hDPSCs were infected with lentivirus in the presence of polybrene $(6 \mu \mathrm{g} / \mathrm{mL}$; Sigma-Aldrich, St. Louis, MO, USA) for $12-24 \mathrm{~h}$. The infection efficiency was evaluated by fluorescent microscope, qRT-PCR and Western blot.

\section{CCK-8 cell proliferation assay}

To assess the effect of Panx3 on the proliferation of hDPSCs, CCK-8 (Dojindo Molecular Technology, Kumamoto, Japan) assay was performed. $10 \mu \mathrm{l}$ CCK-8 mixed with $90 \mu \mathrm{l}$ complete medium was added to each well for incubation $2 \mathrm{hr}$. The absorbance of the supernatant was read at $450 \mathrm{~nm}$ using a microplate reader (PowerWave XS2, BioTek, USA).

\section{ALP staining and Alizarin red staining}

Transduced hDPSCs were cultured in OM for indicated period prior to the following procedures. Cells were fixed in 4\% paraformaldehyde for $15 \mathrm{~min}$ and washed twice with PBS. ALP staining solution containing naphthol AS-MX phosphate (Sigma-Aldrich) and fast red violet LB salt (Sigma-Aldrich) was freshly prepared and added into the wells, and then incubated at $37^{\circ} \mathrm{C}$ for $30-60 \mathrm{~min}$. The wells were photographed and the percentages of ALP-positive cells in each group were calculated.

After culture in $\mathrm{OM}$ for $14 \mathrm{~d}$, the mineralized nodule formation was assessed by staining with $2 \%$ alizarin red solution $(\mathrm{pH}=4.2)$. After incubation for $30 \mathrm{~min}$ at $37^{\circ} \mathrm{C}$, the non-specific staining was washed with distilled water twice. Then the plates were photographed. For quantitative analysis, the mineralized nodule was desorbed with $10 \%$ (w/v) cetylpyridinium chloride (Sigma-Aldrich) for $30 \mathrm{~min}$. The OD values of the supernatants were measured at $570 \mathrm{~nm}$ on an absorbance microplate reader and normalized to total protein concentration.

\section{ALP activity}

At the designated time point, ALP activity was processed. The cells were lysed by $1 \%$ triton for 30 min, and then fresh p-nitrophenyl phosphate (p-NPP) (Sigma-Aldrich) as substrate was incubated at $37^{\circ} \mathrm{C}$ for $15 \mathrm{~min}$. The OD values were read spectrophotometrically at $405 \mathrm{~nm}$. The p-Nitrophenol (Sigma-Aldrich) was used for fabrication of the standard curve. Relative ALP activity was normalized by the total protein concentration. 


\section{Cellular Physiology Cell Physiol Biochem 2017;44:2174-2188 \begin{tabular}{l|l|l} 
and Biochemistry Published online: December 13, 2017 & $\begin{array}{l}\text { (c) } 2017 \text { The Author(s). Published by S. Karger AG, Basel } \\
\text { www.karger.com/cpb }\end{array}$ \\
\hline
\end{tabular}}

Song et al.: Panx3 Promotes Osteogenesis of Hdpscs in Vitro and in Vivo

Table 1. Primer sequences for qRT-PCR

\begin{tabular}{lll}
\hline Gene & Forward primer $\left(5^{\prime}-3^{\prime}\right)$ & Reverse primer $\left(5^{\prime}-3^{\prime}\right)$ \\
\hline Pannexin3 (Panx3) & GACTCACTGCTTCACCATA & GCTCATTCCAGAACACATAG \\
ALP & GTCACTCATTGCTGAGCCTCT & AGCTTCTTCCCACCCACAAG \\
Runx2 & TCAATATTAGAGTCTCAACCCCCA & TTCTCTTTCGTTCCCGGTGG \\
OPN & CATCACCATCTTCCAGGAG & AGGCTGTTGTCATACTTCTC \\
Panx3-promoter & CGGGGTACCactgcatccttatggtatgtgaat & CCGCTCGAGatgatgctgctgagcttgggggtg \\
Panx3-CDS & CCGGAATTCatgtcacttgcacacaca & CGCGGATCCaagctttcttgctccat \\
GAPDH & TGAACGCTGCTTACATGCCA & AGGCTGTTGTCATACTTCTC \\
\hline
\end{tabular}

qRT-PCR

Total RNA was collected from cultured cells using TRIzol (Invitrogen, MA, USA). 1ug RNA was used to transcribe by using PrimeScript ${ }^{\mathrm{TM}}$ RT Reagent Kit with gDNA Eraser (Takara Bio Inc). Then, qRT-PCR was run on the ABI-7500 Real-Time PCR System (Applied Biosystems, CA, USA) with the SYBR Green I dye (Takara) in triplicates. The glyceraldehyde 3-phosphate dehydrogenase (GAPDH) was used as an internal control. The sequences of primers were listed in Table 1. $2^{\wedge-\Delta \Delta C t}$ was used to calculate the relative fold change of gene expression.

\section{Western blot analysis}

Total protein was collected from hDPSCs using RIPA lysis buffer supplemented with PMSF (Roche Applied Science, Mannheim, Germany) and phosphatase inhibitors (Roche Applied Science), and then protein concentration was determined using a BCA assay kit. Next, equal amounts of proteins were loaded on SDS-PAGE gel and transferred to methanol treated PVDF membrane. After blocking with 5\% non-fat milk, the membranes were incubated with anti-Panx3 (Invitrogen), anti- Dentin sialoprotein (DSP) (Santa Cruz, CA, USA), anti-phospho- $\beta$-catenin (Cell Signaling Technology, Danvers, MA, USA), anti- $\beta$-catenin (Abcam, Cambridge, MA, USA), anti-ERK1/2 (Cell Signaling Technology), anti-phospho-ERK1/2 (Cell Signaling Technology) antibodies at $4^{\circ} \mathrm{C}$ with constant rocking and then incubated with horseradish peroxidase (HRP)labeled secondary antibody (Biosharp, Hefei, China) for $1 \mathrm{hr}$ at room temperature. The HRP Conjugated AntiGAPDH (1:10, 000, mouse monoclonal) antibody was used as an internal control. The immunoblots were detected using an ECL kit, and visualized using X-ray film. The relative density was calculated by image J (National Institutes of Health).

\section{Dual luciferase reporter assay}

hDPSCs were transducted with $0.5 \mu \mathrm{g}$ Panx3-promoter or $0.5 \mu \mathrm{g}$ empty pGL3-Basic vectors and $0.05 \mu \mathrm{g}$ pRL-TK plasmid by using Lipofectamine 2000 following the manufacturer's instructions. After transfection for $6 \mathrm{hr}$, the supernatants were discarded and replaced with fresh medium supplemented with LiCl (20 $\mathrm{mM}$ ) or vehicle for another $24 \mathrm{hr}$. Firefly and Renilla luciferase activities were measured using the Dual Glo luciferase assay system (Promega) according to the manufacturer's instructions (Promega). The ratio of Panx3-promoter/ pGL3-Basic was then analyzed.

Transfected hDPSCs were co-transfected with the reporter plasmid TOPflash or FOPflash and the internal control plasmid pRL-TK at a ratio of 10:1. The ratio of TOPflash/FOPflash was analyzed.

\section{Animal experiments}

The bone-forming ability of transfected cells in scaffolds was assessed in a calvarial critical-sized defect model of SD rats. All the animal procedures were approved by the Institutional Ethical Board of Wuhan University and conducted in accordance with the NIH guidelines. For cell seeding, the genetically modified hDPSCs were concentrated to $1 \times 10^{6}$ cells per $50 \mu \mathrm{l}$ of the medium and then dropped on $30 \mathrm{mg}$ of wet $\beta$-TCP particles (diameter $<1 \mathrm{~mm}$, pore size $\approx 500 \mu \mathrm{m}$, porosity $\approx 75 \%$; Shanghai Bio-lu Biomaterials Co., Ltd, China). Twelve 8-week-old male SD rats were purchased from the Hubei Research Center of Laboratory 


\section{Cellular Physiology Cell Physiol Biochem 2017;44:2174-2188 \begin{tabular}{l|l} 
and Biochemistry Published online: December 13, 2017 & $\begin{array}{l}\text { (c) } 2017 \text { The Author(s). Published by S. Karger AG, Basel } \\
\text { www.karger.com/cpb }\end{array}$
\end{tabular}}

Song et al.: Panx3 Promotes Osteogenesis of Hdpscs in Vitro and in Vivo

Animals and housed under specific pathogen free-condition in the laboratory. A 5-mm-diameter defect was drilled on both sides of rat calvarial bones. All of the 24 critical-sized defects were divided into four groups: blank group ( $n=6), \beta$-TCP group $(n=6)$, hDPSCs/Plvx- $\beta$-TCP group $(n=6)$, and hDPSCs/Panx3- $\beta$-TCP group $(n=6)$.

\section{Micro-CT}

All rats were sacrificed 8 weeks postoperation, the calvarial bones were harvested and fixed in $4 \%$ paraformaldehyde. All samples were scanned using $\mu$ CT50 imaging system (Scanco Medical, Switzerland) with the same parameters used previously [21]. Bone formation volume was calculated for bone regeneration.

\section{Histological evaluation}

All samples were decalcified using 10\% EDTA until could be penetrated by needle without resistance before embedding in paraffin. HE, Masson and TRAP staining were conducted separately on serial sections. Masson staining was conducted according to the manufacturer's instructions (Maixin Biotech, Fuzhou, China). A leukocyte-specific acid phosphatase kit (Sigma-Aldrich) was used to detect Tartrate-resistant acid phosphatase (TRAP) activity. For morphometric analysis, newly formed bone area fold changes in Massonstained sections were quantified in 5 sections of at least 5 different defects for each group.

\section{Double immunofluorescence staining for OCN and GFP}

Sections were incubated with the mixture of rabbit anti-Osteocalcin (OCN) (Santa Cruz) and mouse anti-GFP (Santa Cruz). The mixture of DyLight 488-Conjugated Goat Anti-Rabbit (Abbkine, Calif, USA) and DyLight 549-Conjugated Goat Anti-Mouse (Abbkine, Calif, USA) secondary antibodies was used to bind primary antibodies. Then the sections were mounted using mounting medium with 4,6-diamidino-2phenylindole (DAPI) (ZSGB-Bio, Beijing, China), and photographed.

\section{Statistical analysis}

All experiments were independently repeated at least three times. The data were presented as the means \pm SEM. Comparisons were determined by using a two-tailed Student's t-test between two groups; One-way ANOVA was used for more than two groups. $\mathrm{P}<0.05$ were considered as statistically significant.

\section{Results}

\section{Endogenous Panx 3 expression during osteogenic differentiation of hDPSCs}

To elucidate whether the expression of endogenous Panx3 was influenced upon osteogenic differentiation of hDPSCs, hDPSCs were incubated in OM. The results showed that Panx3 expression was significantly enhanced at days 4 and 7 compared to day 0 (Fig. $1 \mathrm{~A}-\mathrm{C})$. These findings indicated that Panx3 might participate into osteogenic differentiation of primary hDPSCs.

Panx3 is required for proliferation and osteogenic differentiation of hDPSCs

For functional analysis of Panx3, we overexpressed and silenced Panx3 expression using lenti-Panx3, lenti-Plvx, lenti-shRNA-Panx3 and lenti-shRNA-Ctrl lentiviruses. Transduction efficiencies of the lentiviruses were verified by fluorescence microscopy (Fig. 1D), qRT-PCR (Fig. 1E, F) and Western blot (Fig. 1G, H).

To analyze the effect of Panx3 on the proliferation of hDPSCs, CCK-8 assay was performed. The proliferation rate was significantly decreased in hDPSCs/Panx3 cells compared with that in hDPSCs/Plvx cells. Furthermore, Panx3 knockdown enhanced cell proliferation compared with that in control cells (Fig. 2A). Meanwhile, p21 mRNA expression level was upregulated in hDPSCs/Panx3 but decreased in hDPSCs/shRNA compared with respective control groups (Fig. 2B).

To further evaluate the effect of Panx3 in osteogenic differentiation of hDPSCs, the four groups were induced to differentiation. We found that overexpression of Panx3 promoted differentiation of hDPSCs as evidenced by increased expression of mineralization-related 


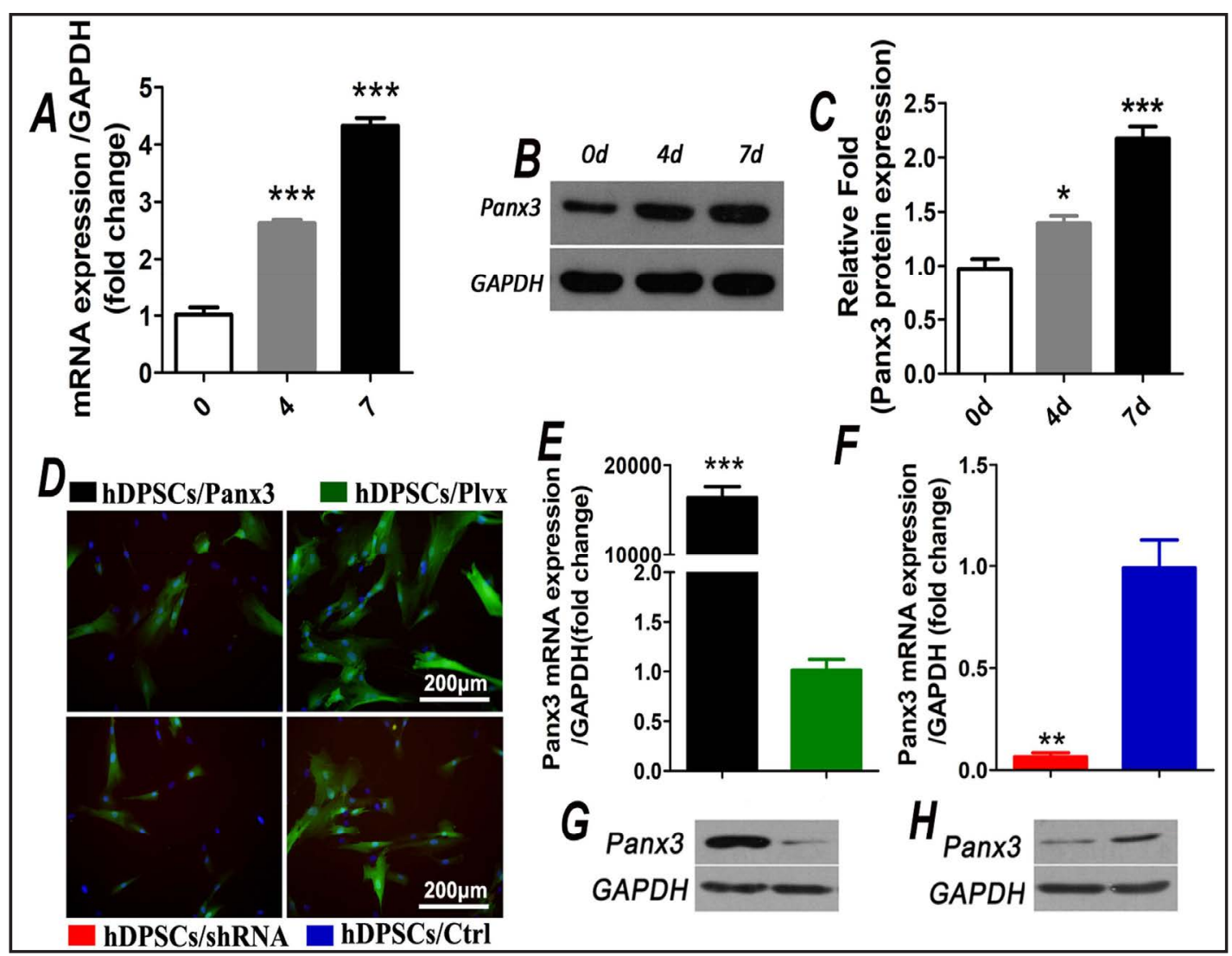

Fig. 1. Endogenous Panx3 expression and construction of Panx3-overexpression hDPSCs or Panx3inhibition hDPSCs. (A) Endogenous mRNA level of Panx3 was detected by qRT-PCR at day 0, 4, 7 during osteogenic differentiation of hDPSCs. GAPDH was used as internal control, and the value was normalized to day 0 . (B, C) The endogenous protein level of Panx3 was determined by western lot. Histogram represents quantifications of Western blot results relative to GAPDH. (D) hDPSCs after transfection with lenti-Panx3, lenti-plvx, lenti-shRNA-Panx3 and lenti-shRNA-Ctrl lentivirals for $48 \mathrm{~h}$ were counterstained with DAPI and observed using a fluorescence microscope, and the cells were named as hDPSCs/Panx3, hDPSCs/Plvx, hDPSCs/shRNA and hDPSCs/Ctrl, respectively. Scale bar: $200 \mu \mathrm{m}$. (E-H) Validation of Panx3 overexpression and knockdown by lentivirus were assessed by qRT-PCR (E, F) and western blot (G, H). GAPDH was used as an internal control. Data are presented as mean \pm SEM. $(n=3){ }^{*} p<0.05,{ }^{* *} p<0.01,{ }^{* * *} p<0.001$ versus control.

markers, higher ALP activity (Fig. 2C-G) and enhanced in vitro extracellular matrix (ECM) formation visualized by ALP staining and alizarin red staining (Fig. $2 \mathrm{H}-\mathrm{J}$ ). By contrast, Panx3 knockdown remarkably diminished the osteogenic differentiation of hDPSC (Fig. 2C-J).

Panx3 represses the Wnt/ $\beta$-catenin signaling pathway and the promotive effect of Panx 3 on osteogenic differentiation is not dependent on the Wnt/ $\beta$-catenin signaling pathway

Wnt/ $\beta$-catenin signaling plays critical roles in developmental processes such as differentiation, proliferation and bone regeneration. Therefore, we investigated the effect of Panx3 on this pathway. Some commonly used markers of Wnt/ $\beta$-catenin activation are (a) the phosphorylation level of $\beta$-catenin, (b) the nuclear translocation of $\beta$-catenin, (c) the interaction between $\beta$-catenin and TCF/LEF transcription factor. In our investigations, western blot analysis showed that Panx3 overexpression increased the phosphorylation level of $\beta$-catenin, but decreased total $\beta$-catenin expression (Fig. 3A). Immunofluorescence analysis demonstrated that Panx3 overexpression exhibited weaker nuclear staining of $\beta$-catenin compared to control cells (Fig. 3B). In addition, the mRNA expression of $\beta$-catenin was enhanced in hDPSCs/shRNA cells but decreased in the hDPSCs/Panx3 group (Fig. 3C). In 


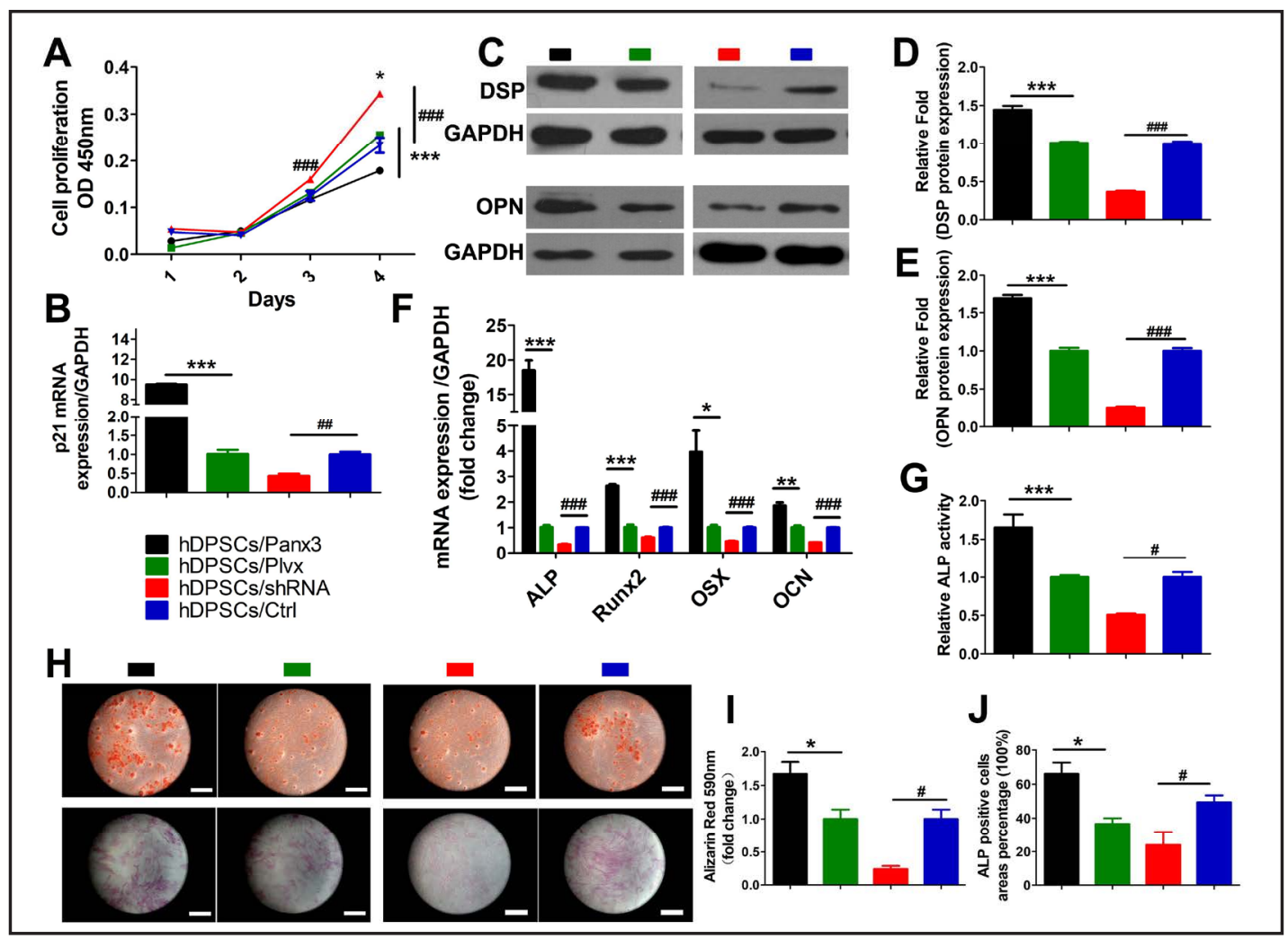

Fig. 2. The effect of Panx3 on proliferation and osteogenic differentiation of hDPSCs. (A) CCK8 assay at daily intervals over 4 days' incubation. (B) p21 mRNA expression was detected by qRT-PCR and normalized to GAPDH. (C) The protein expression of DSP and OPN were determined by western blot. (n=3) (D, E) Histogram represents quantification of DSP and OPN proteins obtained by Image J software. (F) Mineralization-related genes including ALP, Runx2, OSX and OCN were determined by qRT-PCR at day 7. The values of $2^{\wedge}-\Delta \Delta \mathrm{ct}$ were used for statistical analysis. (G) ALP activity was measured at 7 day of differentiation. (H) Alizarin red staining was performed at day 14. ALP staining was performed at day 7. Scale bar: $500 \mu \mathrm{m}$. (I) Histogram shows the relative quantification of alizarin red s staining by measuring the absorbance at $560 \mathrm{~nm}$. (J) ALP staining was performed at day 7. Histogram shows the percentage of ALP-positive cell area. Results are shown as mean \pm SEM. ${ }^{*} \mathrm{p}<0.05,{ }^{* *} \mathrm{p}<0.01,{ }^{* * *} \mathrm{p}<0.001$, hDPSCs/Panx3 versus hDPSCs $/$ Plvx; \# $\mathrm{p}<0.05$, \#\# $\mathrm{p}<0.01,{ }^{\# \# \#} \mathrm{p}<0.001$, hDPSCs/shRNA versus hDPSCs.

contrast, Panx3-knockdown cells showed adverse tendency compared with control cells (Fig. $3 \mathrm{~A}$ ). To assess whether the transcriptional activities of $\beta$-catenin were regulated by Panx3, we performed a TOPflash/FOPflash luciferase reporter assay in hDPSCs. Dual-luciferase reporter assay showed that Panx3 overexpression retarded Wnt/ $\beta$-catenin transcription activity by $66 \%$, and Panx3 knockdown increased it by approximately 1.2 -fold upon 20 $\mathrm{mM} \mathrm{LiCl}$ stimulation for $24 \mathrm{hr}$ (Fig. 3D). Taken together, these findings suggest that Panx3 inactivated Wnt/ $\beta$-catenin in hDPSCs.

To investigate whether Panx3 positively controls differentiation via inactivation of Wnt/ $\beta$-catenin, we used $\mathrm{LiCl}$ to activate $\mathrm{Wnt} / \beta$-catenin signaling and attempted to reverse the higher differentiation abilities of the hDPSCs/Panx3 group. Surprisingly, instead of reversing the promoting effect of Panx3 overexpression on differentiation, LiCl even enhanced the effect. In addition, expressions of mineralization-related markers were significantly increased in LiCl-treated hDPSCs/shRNA cells than that in untreated groups (Fig. 3E-H). Overall, these data showed that Wnt/ $\beta$-catenin did not contribute to increase in osteogenic differentiation in the hDPSCs/Panx3 group. 


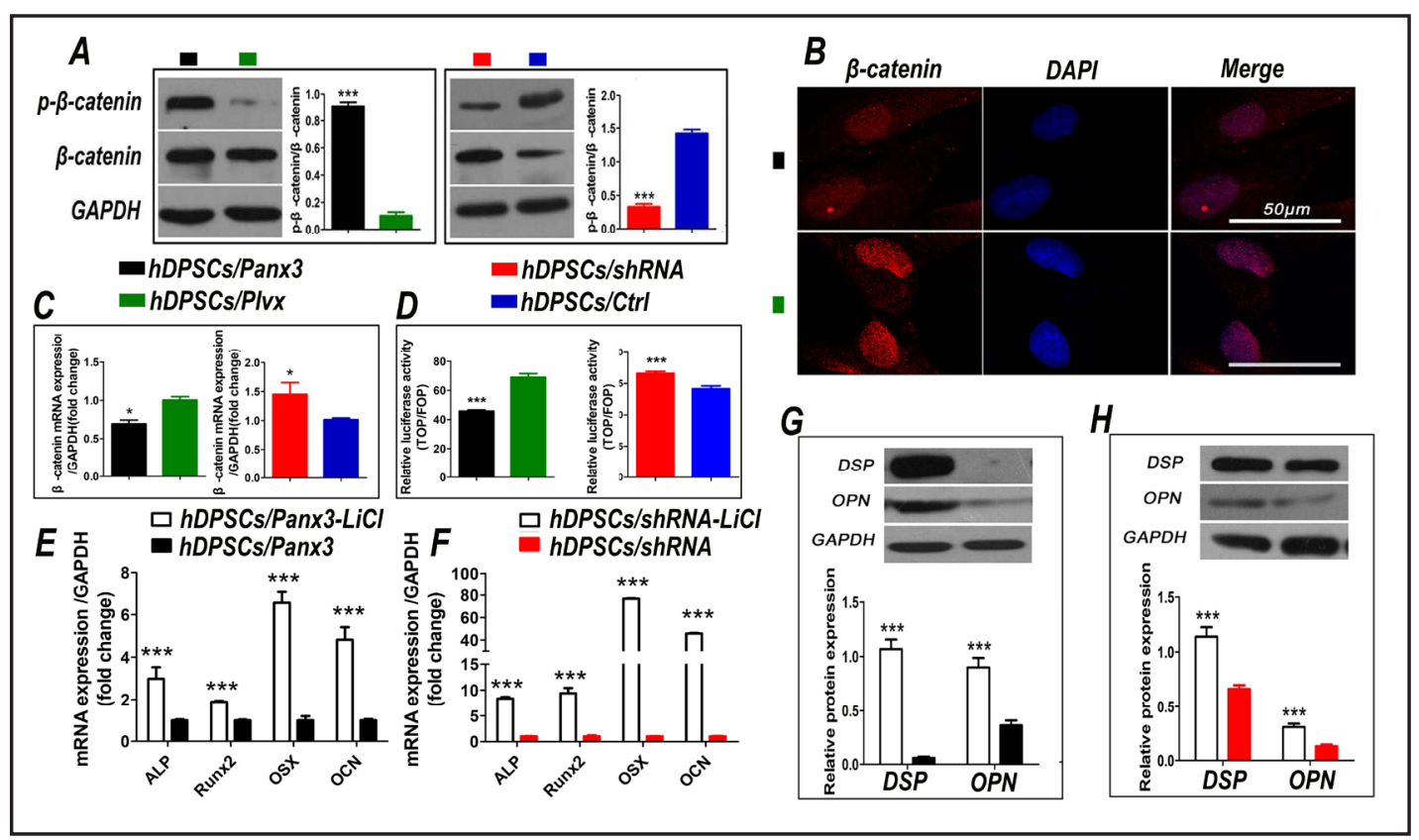

Fig. 3. Panx3 inactivated the Wnt/ $\beta$-catenin signaling pathway. (A) p- $\beta$-catenin, $\beta$-catenin and GAPDH immunoblot, with quantification of $p$ - $\beta$-catenin to $\beta$-catenin ratio. (B) Representative confocal images of anti$\beta$-catenin immunofluorescence staining of hDPSCs/Panx3 (upper) and hDPSCs/Plvx (lower) cells treated with $20 \mathrm{mM} \mathrm{LiCl}$ for $24 \mathrm{hr}$. Scale bar: $50 \mu \mathrm{m}$. (C) qRT-PCR analysis of $\beta$-catenin mRNA level in transfected hDPSCs. (D) Relative luciferase activity (RLU) of TOPFlash/FOPFlash in transfected hDPSCs treated with $20 \mathrm{mM}$ GSK3 $\beta$ inhibitor $\mathrm{LiCl}$ for $24 \mathrm{hr}$. (E, F) Mineralization-related genes were determined by qRT-PCR in transfected hDPSCs treated with or without LiCl after 7d induction. (G, H) Representative images and quantitation of DSP and OPN expression of transfected hDPSCs cultured for 7d treated with or without LiCl $(20 \mathrm{mM})$. Results are shown as mean \pm SEM. ${ }^{*} \mathrm{p}<0.05,{ }^{* * *} \mathrm{p}<0.001$ versus control.

\section{Panx3 is a target of Wnt/ $\beta$-catenin}

Subsequently, we investigated whether Panx3 expression is affected by Wnt/ $\beta$-catenin signaling. Using Genomatix MatInspector software, we found TCF/LEF binding sites within the candidate promoter sequence of Panx3. We then screened the Panx3 promoter regions from mammalian species, human, canine, and mice, for potential TCF/LEF-binding sites (Fig 4A). All three Panx3 promoters in both directions contained the TCF/LEF consensus sequence A/TA/TCAAAG $[22,23]$. This suggested that Panx3 might be a target of the Wnt/ $\beta$ catenin signaling pathway. We then treated hDPSCs cells with Wnt3a-conditioned medium or $\mathrm{LiCl}$ for up to $24 \mathrm{~h}$ and performed Western blot analysis. Similar to $\beta$-catenin expression, Wnt3a-conditioned medium $(0,10 \%, 20 \%, 40 \%$ and $80 \%)$ and $\mathrm{LiCl}(0,5 \mathrm{mM}, 10 \mathrm{mM}, 20 \mathrm{mM})$ progressively enhanced Panx3 protein expression (Fig. 4B, C). We then genetically repressed Wnt/ $\beta$-catenin signaling activity using $\beta$-catenin-shRNA. Knockdown of $\beta$-catenin lessened Panx3 expression (Fig. 4D). Immunofluorescence analysis confirmed these results (Fig. 4E). Next, we cloned the potential human Panx3 promoter (the 5'-flanking 2-kb region of the Panx3 gene transcription start site) into the pGL3-basic luciferase reporter vector (Fig. 4F) and performed dual-luciferase reporter experiments. Dual-luciferase assay showed that LiCl considerably enhanced the Panx3 promoter activity (Fig. 4G). These findings indicate that Wnt/ $\beta$-catenin positively regulates Panx3 expression.

Panx 3 controls differentiation of hDPSCs via activation of the ERK1/2 signaling pathway

ERK signaling pathway is a critical regulator of MSCs and positively modulate osteogenic differentiation [24]. Western blot analysis showed enhanced phosphorylation level of ERK1/2 in the hDPSCs/Panx3 group, whereas p-ERK1/2 level was decreased in the hDPSCs/shRNA group (Fig. 5A). Accordingly, U0126, a specific inhibitor of the ERK1/2 signaling pathway, 


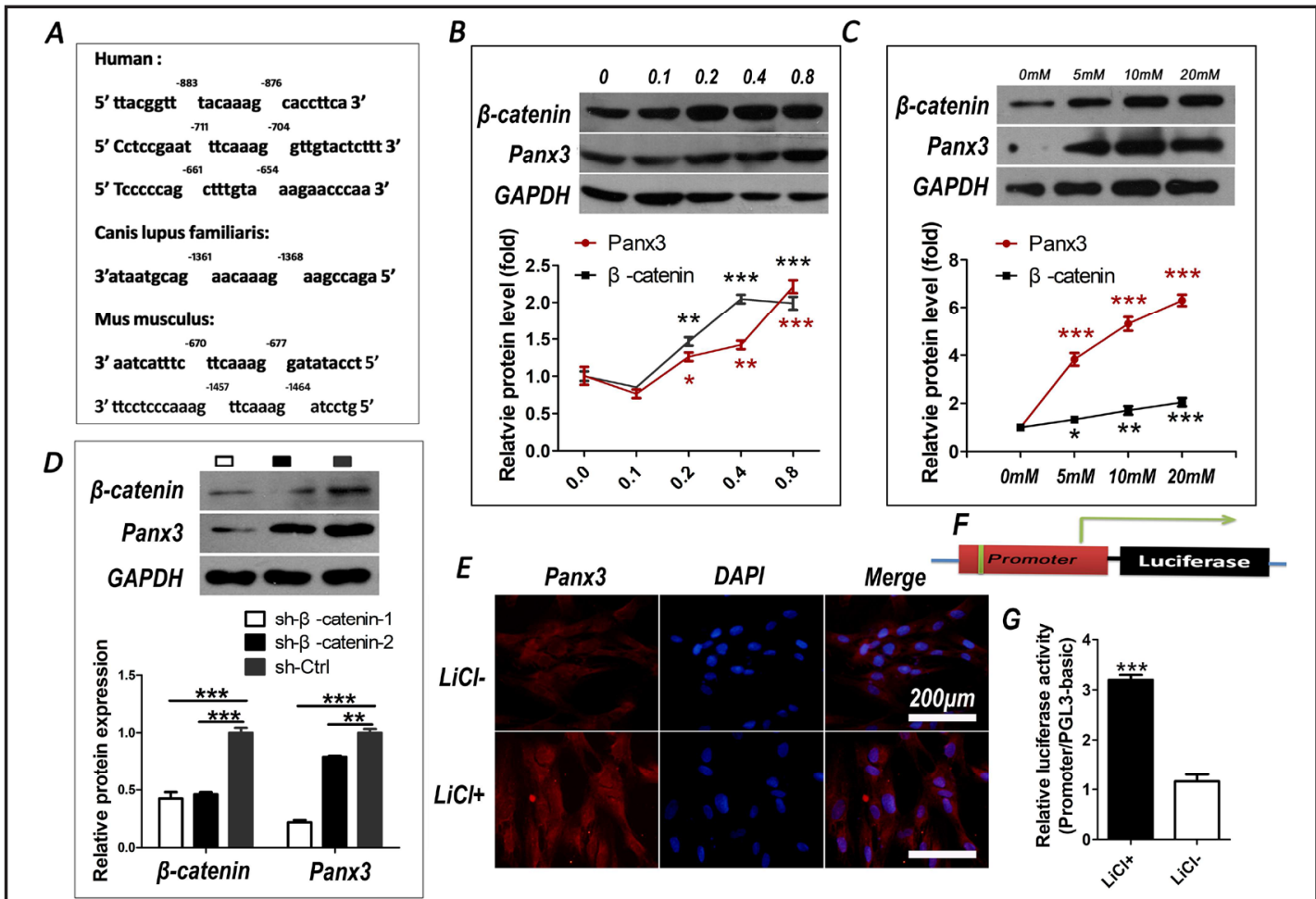

Fig. 4. Wnt/ $\beta$-catenin transcriptionally regulated Panx3 expression. (A) Screen of TCF/LEF consensus binding sites in putative Panx3 promoter sequences from three mammal species. (B, C) Western blot (upper panel) and quantification (lower panel) of $\beta$-catenin and Panx3 in response to different concentration of Wnt3a-conditioned medium (B) and $\mathrm{LiCl}$ (C). (D) Western blot (upper panel) and quantification (lower panel) of $\beta$-catenin and Panx3 in sh- $\beta$-catenin- 1 , sh- $\beta$-catenin- 2 and control groups. (E) Representative images of anti-Panx3 immunofluorescence staining in hDPSCs treated with or without $20 \mathrm{mM} \mathrm{LiCl}$ for $24 \mathrm{hr}$. Scale bar: $200 \mu \mathrm{m}$. (F) Schematic of the luciferase vector. (G) Panx3-luciferase assays of hDPSCs cells treated with $20 \mathrm{mM} \mathrm{LiCl}$ or not for $24 \mathrm{hr}$. RL-TK was used to normalize transduction efficiency. PGL3-basic vector was used as a negative control. The ratio of Panx3 promoter/PGL3-basic was used for statistical analysis. $(\mathrm{n}=3)$ Results are shown as mean $\pm \mathrm{SEM},{ }^{*} \mathrm{p}<0.05$, ${ }^{* *} \mathrm{p}<0.01,{ }^{* * *} \mathrm{p}<0.001$, versus Control.

significantly impaired the effect of Panx3 on osteogenic differentiation, including reduced expression of mineralization-related markers, lessened ALP activity, and less mineralization of ECM as assessed by ARS staining (Fig. 5B-F) in the U0126-treated hDPSCs/Panx3 group compared with those in the hDPSCs/Panx3 group. Collectively, these results demonstrate that Panx3 promotes osteogenic differentiation by upregulating ERK signaling pathway.

\section{Reinforced Panx 3 overexpression accelerates bone repair in vivo}

To support the in vitro results that Panx3 promotes osteogenic differentiation of hDPSCs, we next analyzed the ability of Panx3 for bone repair by using a rat cranial critical-sized bone defect model. $\mu$ CT (Fig. 6A, the first line) and histomorphometric analysis (Fig. 6B) showed that hDPSCs/Panx3- $\beta$-TCP group displayed more bone formation than hDPSCs/Plvx- $\beta$-TCP at 8 weeks post-operation even though the defect was not completely restored. A small amount of newly formed bone was detected in the $\beta$-TCP only group, and almost no newly formed bone was detected in the blank group.

Histological analysis showed that the newly formed bone area in the hDPSCs/Panx3- $\beta$ TCP group was 1.8-fold greater than that in the hDPSCs/Plvx- $\beta$-TCP group (Fig. 6A, C). The $\beta$-TCP alone group showed higher bone formation than blank group. The scaffolds almost degraded in 8 weeks. Hardly any newly formed bone was present in the blank group. TRAP 
Fig. 5. Panx3 promotes osteogenic differentiation of hDPSCs by positively regulating the ERK1/2 signaling pathway. (A) p-ERK1/2 and ERK1/2 immunoblot of hDPSCs/Panx3, hDPSCs/Plvx, hDPSCs/ shRNA and hDPSCs/Ctrl cells, with quantification of p-ERK/ERK. (B) Expression of ALP, Runx2, OSX and OCN were determined by qRT-PCR. (C) ALP activity. (D) DSP, OPN and GAPDH immunoblot, with quantification of DSP and OPN. (E) Alizarin red staining was performed at day 14. Scale bar: $500 \mu \mathrm{m}$. (F) Quantification of Alizarin red staining. $(n=3)$ Results are shown as mean \pm SEM, ${ }^{*} \mathrm{p}<0.05$, ** $\mathrm{p}<0.01$, *** $\mathrm{p}<0.001$ versus control groups; \#\# $\mathrm{p}<0.001$ hDPSCs/shRNA versus hDPSCs.
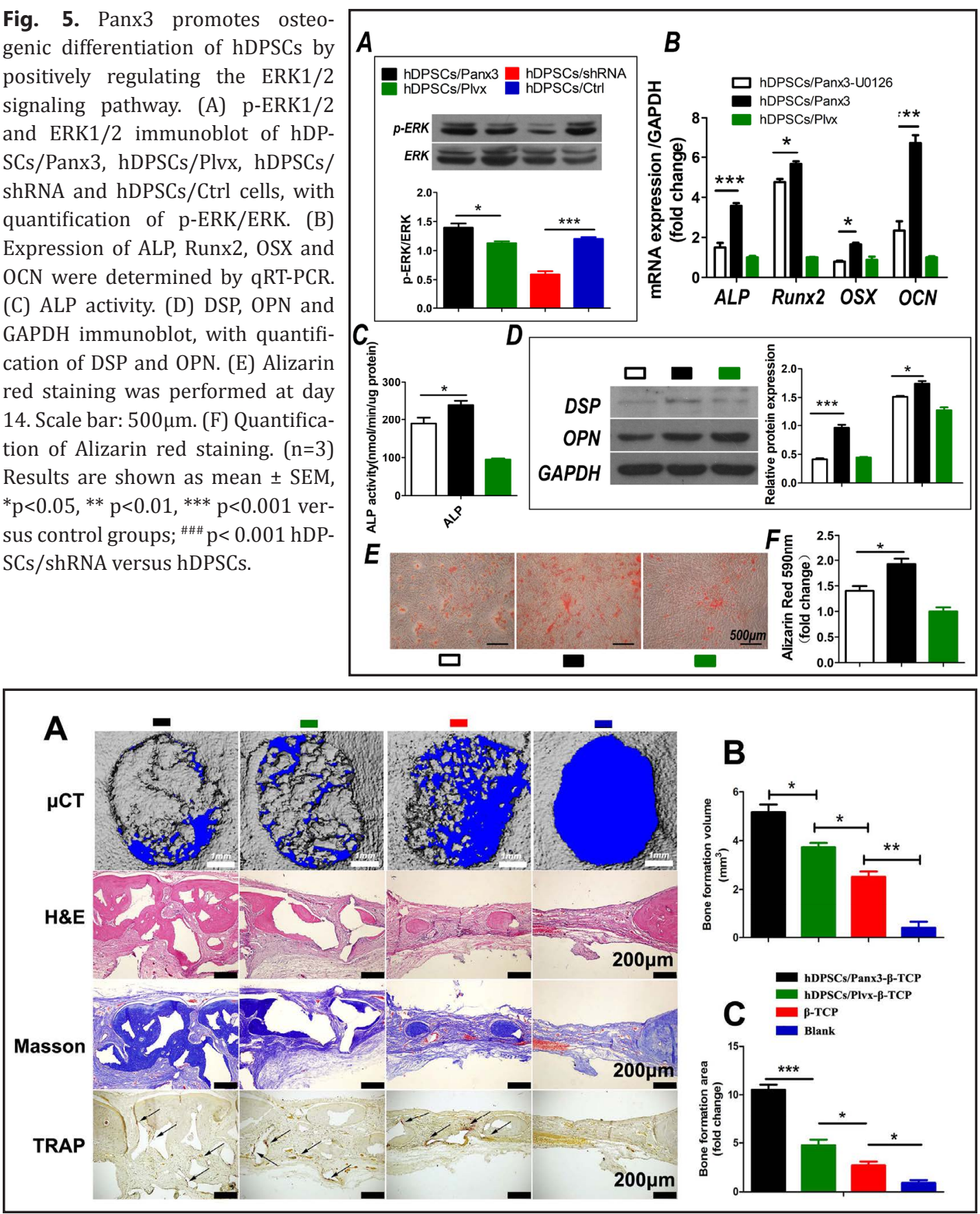

Fig. 6. Panx3-modified hDPSCs increases bone repair in vivo. (A) Micro-CT images of the cranial bone defect sites in each group at 8 weeks after surgery. Scale bar $=1 \mathrm{~mm}$. HE staining. Scale bar: $200 \mu \mathrm{m}$. Masson trichrome staining. Scale bar: $200 \mu \mathrm{m}$. TRAP staining. Scale bar: $200 \mu \mathrm{m}$. (B, C) Analysis of new bone formation volume by micro-CT (B), new bone formation area fold change by HE staining (C). Results are shown as mean \pm SEM, ${ }^{*} \mathrm{p}<0.05,{ }^{* *} \mathrm{p}<0.01,{ }^{* * *} \mathrm{p}<0.001 . \mathrm{n}=6$. From left to right: hDPSCs/Panx3- $\beta-T C P$, hDPSCs/Plvx- $\beta$ TCP, $\beta$-TCP only, blank. The arrows indicate TRAP+ cells.

staining showed that osteoclasts were presented in the border of the newly formed bone (Fig. 6A, the last line).

To identify the origin and status of implanted hDPSCs in newly formed bone, double immunofluorescence staining of OCN and GFP was performed (Fig. 7). GFP-positive cells 


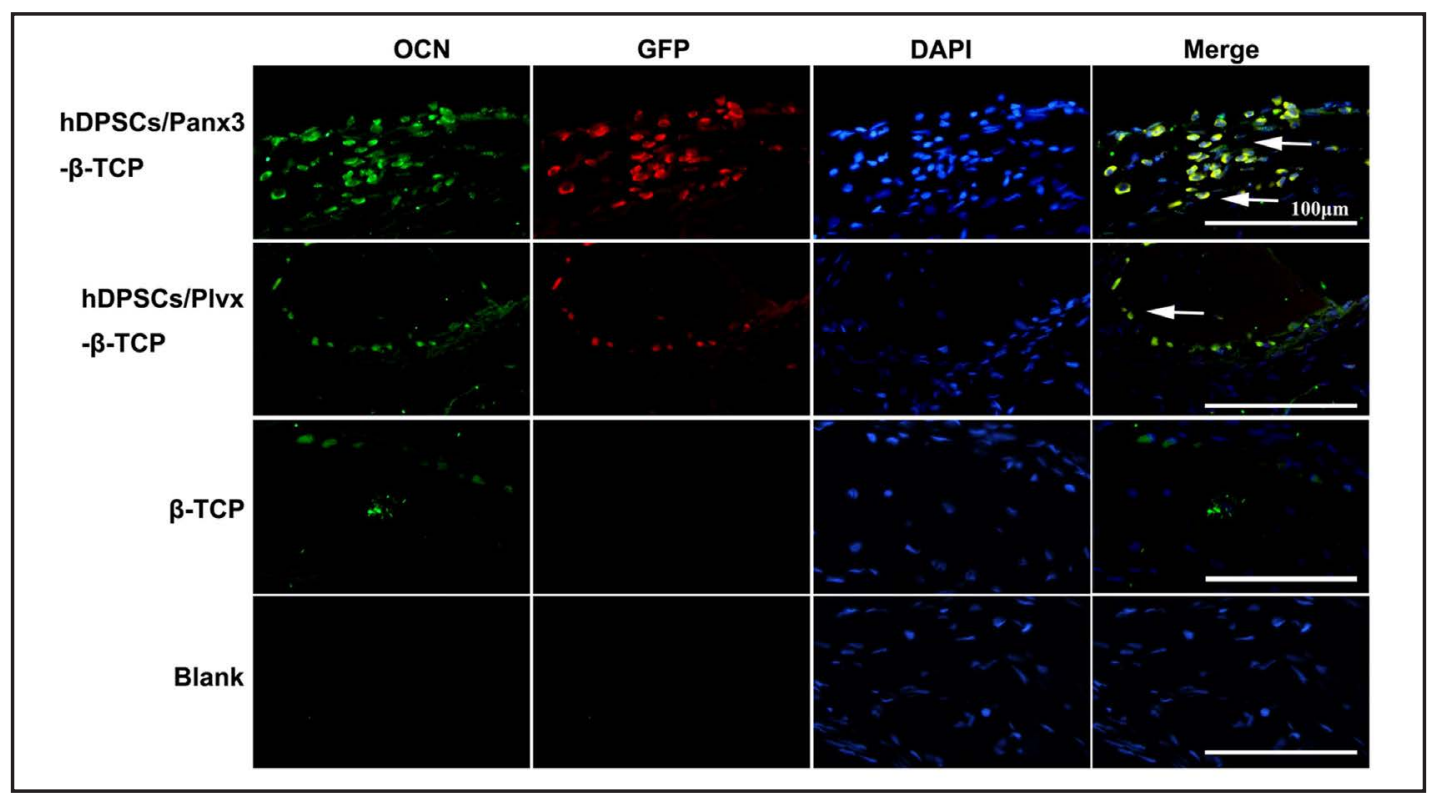

Fig. 7. Double immunofluorescence staining for OCN and GFP 8 weeks after surgery in each group. OCN protein was stained with green color, and GFP protein was stained with red color. Nuclei were counterstained with DAPI. Scale bar: $100 \mu \mathrm{m}$. Arrows indicate GFP+/OCN+ cells.

confirmed the species specificity. hDPSCs/Panx3- $\beta$-TCP and hDPSCs/Plvx- $\beta$-TCP groups clearly stained positive for GFP. Meanwhile, more OCN-positive cells significantly appeared at the newly formed bone sites in the hDPSCs/Panx3- $\beta$-TCP group than that in the other three groups. Minimum expression of OCN was displayed in the blank group. Taken together, these data confirm the long-term osteogenesis of these transducted hDPSCs loaded onto $\beta$-TCP scaffold; moreover, Panx3-modified hDPSCs enhanced bone formation in vivo.

\section{Discussion}

hDPSCs have been increasingly exploited as seed cells for cell-based bone regeneration, which has motivated research in the field of hDPSCs differentiation. The development of gene therapy has become one of most promising hot points for bone tissue engineering. To date, no reports have been published on the effect of Panx3 on osteogenic differentiation of hDPSCs in vitro and in vivo. This study is the first to investigate these phenomena.

In the present study, we showed that Panx3 was upregulated upon osteogenic commitment. Accordingly, Panx3 overexpression inhibits proliferation and promotes differentiation of hDPSCs, whereas Panx3 silencing plays an opposite effect on proliferation and differentiation. Moreover, in vivo experimental results revealed that Panx3 overexpressing hDPSCs accelerate new bone formation and healing of bone defects. This is consistent with previous studies that Panx3 positively regulates osteogenesis of mice pre-osteoblasts. Ishikawa et al. demonstrated that Panx3 functions as a hemichannel allowing intracellular ATP release into the extracellular space. Extracellular ATP binds to purinergic receptors, activating PI3K/Akt and thereby influencing key downstream factors involved in osteogenic differentiation [15]. However, the molecular mechanisms behind Panx3 function during osteogenic differentiation of hDPSCs are still undefined.

A previous study showed that Panx3 could inhibit proliferation of murine osteoprogenitors through inhibition of the Wnt signaling pathway [25]. Wnt/ $\beta$-catenin signaling pathway not only regulates cell proliferation but also orchestrates differentiation in various cell types. Notably, Wnt/ $\beta$-catenin has been demonstrated to play a controversial

\section{KARGER}




\section{Cellular Physiology Cell Physiol Biochem 2017;44:2174-2188 \\ \begin{tabular}{l|l} 
DOI: 10.1159/000486023 & $\begin{array}{l}\text { O } 2017 \text { The Author(s). Published by S. Karger AG, Basel } \\
\text { www.karger.com/cpb }\end{array}$
\end{tabular} \\ Song et al.: Panx3 Promotes Osteogenesis of Hdpscs in Vitro and in Vivo}

modulatory role in osteogenic differentiation [26-28]. These discrepancies prompted us to question whether Panx3 regulates osteoblast differentiation of hDPSCs through canonical Wnt/ $\beta$-catenin signaling. In the current study, Panx3 overexpression in hDPSCs inactivated Wnt/ $\beta$-catenin transcriptional activity, whereas Panx3-silencing hDPSCs had an opposite effect. This is in agreement with the study by Ishikawa et al. in which Panx3 was found to promote $\beta$-catenin degradation through GSK3 $\beta$ activation [25]. Therefore, we postulated that Panx3 may regulate differentiation through downregulating $W n t / \beta$-catenin. To test this postulation, hDPSCs/Panx3 cells were incubated with $\mathrm{LiCl}(20 \mathrm{mM})$, a Wnt/ $\beta$-catenin agonist for activating $\mathrm{Wnt} / \beta$-catenin. Instead of reversing the upregulation of mineralization-related markers, LiCl further exacerbated osteogenic differentiation of Panx3-overexpressed cells. $\mathrm{LiCl}$ also promoted the osteogenic differentiation of Panx3 knockdown hDPSCs. Therefore, it is reasonable to conclude that Wnt/ $\beta$-catenin signaling plays a positive role in osteogenic differentiation of hDPSCs, but the promotive effect of Panx3 on differentiation of hDPSCs may not be attributed to suppression of the Wnt/ $\beta$-catenin signaling pathway. This finding is in agreement with a previous study showing that Wnt/ $\beta$-catenin promotes odonto/ osteogenic differentiation of stem cells of dental apical papilla [29].

Up to now, there are a few published studies on the upstream activators of Panx3. Result of bioinformatics analysis revealed that mammal putative Panx3 promoters contain several TCF/LEF binding consensus sites (A/TA/TCAAAG) [22, 23]. In this study, we discovered that both $\mathrm{LiCl}$ and Wnt3a-conditioned medium significantly up-regulated Panx3 protein level, concomitant with increase of $\beta$-catenin. Conversely, deletion of $\beta$-catenin impaired Panx3 protein expression. Wnt3a, one of the receptor ligands of Frizzled, could activate Wnt signaling [22]. LiCl activates the Wnt/ $\beta$-catenin signaling pathway by inhibiting GSK3 $\beta$ [30]. Subsequently, we cloned the 5' proximal region of the human Panx3 promoter into the pGL3-basic vector. Activation of Wnt signaling pathway using $\mathrm{LiCl}$ up-regulated Panx3 promoter activity. Collectively, our studies provide the first evidence that Wnt/ $\beta$-catenin signaling transcriptionally regulates Panx3 expression, and thereby forms a feedback loop.

The ERK signaling pathway is important in osteogenic commitment of various cell types $[24,31,32]$. In the present study, we demonstrated that Panx3 overexpression enhanced ERK activity. Additionally, U0126, an inhibitor of ERK signaling pathway, could retard the enhanced osteogenic differentiation ability of Panx3 overexpression in hDPSCs. However, the molecular mechanism of this cellular event remains elusive. One possible explanation is that Panx3 functions as a hemichannel mediating ATP release from the cytoplasm into extracellular environments [33]. Likewise, extracellular ATP could activate the ERK signaling pathway [34-36], partially explaining the promotive implication of Panx3 on the ERK pathway. Certainly, this is unlikely to be the sole mechanism of Panx3-induced upregulation of osteogenic differentiation.

In order to verify the clinical potential of Panx3-modified hDPSCs in cell-based therapy, a rat cranial critical-sized bone defect model was used to test the bone repair capacity of modified hDPSCs in vivo. In our study, no immune cells were activated and recruited to the injured sites. This is consistent with previous studies that have reported absence of immune rejection and teratoma formation upon transplantation of hDPSCs into immunocompetent animals such as mice, rats and monkeys [37]. Moreover, immunosuppressive activity was higher in hDPSCs than MSCs [38]. Due to their low immunogenicity and low rates of transplantation rejection, it is not necessary to match recipients and donor for hDPSCs transplantation $[39,40]$. A three-dimensional scaffold capable of supporting bone formation is crucial for bone regeneration. $\beta$-TCP scaffold has high porosity and interconnectivity and is a good osteo-conductive material that has been commonly used in bone defects repair [41]. For this reason, $\beta$-TCP was chosen as scaffold in our study. GFP was used as a marker of transplanted cells. Detection of GFP in the osteocytes in hDPSCsS/Panx3- $\beta$-TCP and hDPSCs / Plvx- $\beta$-TCP groups indicates that hDPSCs could survive for a long time and ossify in vivo [42]. In addition, this result showed that Panx3 modified hDPSCs could directly enhance osteogenicity. However, some GFP-/OCN+ cells were detected in all the groups, indicating 


\section{Cellular Physiology Cell Physiol Biochem 2017;44:2174-2188 \begin{tabular}{l|l|l} 
and Biochemistry Published online: December 13, 2017 & $\begin{array}{l}\text { (c) } 2017 \text { The Author(s). Published by S. Karger AG, Basel } \\
\text { www.karger.com/cpb }\end{array}$ \\
\hline
\end{tabular}}

that the bone defects were repaired through the collective effects of both transplanted and host cells.

In summary, our experiments demonstrated that Panx3 plays an essential role in the regulation of osteogenic differentiation by activating ERK signaling pathways. Additionally, our findings indicate a bi-directional interaction between Panx3 and Wnt/ $\beta$-catenin. In a rat cranial critical-sized bone defect model, Panx3-modified hDPSCs could improve bone repair. Collectively, our results provide the first set of evidence supporting the model that Panx3 functions as an endogenous activator of hDPSC osteogenic commitment. Thus, Panx3-modifed hDPSCs show promise for use in bone tissue engineering. Nonetheless, whether the promotive effect of Panx3 on differentiation was a consequence of addition of Panx3 hemichannel function or a systematic Panx3 protein overexpression needs to be distinguished. Moreover, the direct interaction between Panx3 and signaling pathway warrants further exploration.

\section{Acknowledgements}

This work was financially supported by the National Natural Science Foundation of China (81171010 and 81571012) and the Fundamental Research Funds for the Central Universities (2014304020201). The authors thank EssayStar for copyediting this manuscript.

\section{Disclosure Statement}

The authors declare no disclosure statement.

\section{References}

1 Schmitz JP, Hollinger JO: The critical size defect as an experimental model for craniomandibulofacial nonunions. Clin Orthop Relat Res 1986:299-308.

2 Silber JS, Anderson DG, Daffner SD, Brislin BT, Leland JM, Hilibrand AS, Vaccaro AR, Albert TJ: Donor site morbidity after anterior iliac crest bone harvest for single-level anterior cervical discectomy and fusion. Spine (Phila Pa 1976) 2003;28:134-139.

3 Zhang ZY, Teoh SH, Chong MS, Schantz JT, Fisk NM, Choolani MA, Chan J: Superior osteogenic capacity for bone tissue engineering of fetal compared with perinatal and adult mesenchymal stem cells. Stem Cells 2009;27:126-137.

4 Le Blanc K, Pittenger M: Mesenchymal stem cells: Progress toward promise. Cytotherapy 2005;7:36-45.

5 Gronthos S, Mankani M, Brahim J, Robey PG, Shi S: Postnatal human dental pulp stem cells (DPSCs) in vitro and in vivo. Proc Natl Acad Sci U S A 2000;97:13625-13630.

6 Gu S, Ran S, Qin F, Cao D, Wang J, Liu B, Liang J: Human Dental Pulp Stem Cells via the NF-kappaB Pathway. Cell Physiol Biochem 2015;36:1725-1734.

7 Gronthos S, Brahim J, Li W, Fisher LW, Cherman N, Boyde A, DenBesten P, Robey PG, Shi S: Stem cell properties of human dental pulp stem cells. J Dent Res 2002;81:531-535.

-8 La Noce M, Mele L, Tirino V, Paino F, De Rosa A, Naddeo P, Papagerakis P, Papaccio G, Desiderio V: Neural crest stem cell population in craniomaxillofacial development and tissue repair. Eur Cell Mater 2014;28:348-357.

9 Alge DL, Zhou D, Adams LL, Wyss BK, Shadday MD, Woods EJ, Gabriel CT, Goebel WS: Donor-matched comparison of dental pulp stem cells and bone marrow-derived mesenchymal stem cells in a rat model. J Tissue Eng Regen Med 2010;4:73-81.

10 Papaccio G, Graziano A, D’Aquino R, Graziano MF, Pirozzi G, Menditti D, De Rosa A, Carinci F, Laino G: Longterm cryopreservation of dental pulp stem cells (SBP-DPSCs) and their differentiated osteoblasts: A cell source for tissue repair. J Cell Physiol 2006;208:319-325. 


\section{Cellular Physiology Cell Physiol Biochem 2017;44:2174-2188 \begin{tabular}{ll|l} 
and BiOChemistry & $\begin{array}{l}\text { DOI: 10.1159/000486023 } \\
\text { Published online: December 13, } 2017\end{array}$ & $\begin{array}{l}\text { (c) } 2017 \text { The Author(s). Published by S. Karger AG, Basel } \\
\text { www.karger.com/cpb }\end{array}$ \\
\hline
\end{tabular}}

11 D’Aquino R, De Rosa A, Lanza V, Tirino V, Laino L, Graziano A, Desiderio V, Laino G, Papaccio G: Human mandible bone defect repair by the grafting of dental pulp stem/progenitor cells and collagen sponge biocomplexes. Eur Cell Mater 2009;18:75-83.

$\checkmark 12$ Tatullo M, Marrelli M, Shakesheff KM, White LJ: Dental pulp stem cells: Function, isolation and applications in regenerative medicine. J Tissue Eng Regen Med 2015;9:1205-1216.

13 Paino F, La Noce M, Giuliani A, De Rosa A, Mazzoni S, Laino L, Amler E, Papaccio G, Desiderio V, Tirino V: Human DPSCs fabricate vascularized woven bone tissue: A new tool in bone tissue engineering. Clin Sci (Lond) 2017;131:699-713.

14 Giuliani A, Manescu A, Langer M, Rustichelli F, Desiderio V, Paino F, De Rosa A, Laino L, D’Aquino R, Tirino V, Papaccio G: Three years after transplants in human mandibles, histological and in-line holotomography revealed that stem cells regenerated a compact rather than a spongy bone: Biological and clinical implications. Stem Cells Transl Med 2013;2:316-324.

15 Ishikawa M, Iwamoto T, Nakamura T, Doyle A, Fukumoto S, Yamada Y: Pannexin 3 functions as an ER Ca(2+) channel, hemichannel, and gap junction to promote osteoblast differentiation. J Cell Biol 2011;193:12571274.

16 Iwamoto T, Nakamura T, Doyle A, Ishikawa M, de Vega S, Fukumoto S, Yamada Y: Pannexin 3 regulates intracellular ATP/cAMP levels and promotes chondrocyte differentiation. J Biol Chem 2010;285:1894818958.

17 Fan C, Jia L, Zheng Y, Jin C, Liu Y, Liu H, Zhou Y: MiR-34a promotes osteogenic differentiation of human Adipose-Derived stem cells via the RBP2/NOTCH1/CYCLIN d1 coregulatory network. Stem Cell Reports 2016;7:236-248.

18 Wei J, Shi Y, Zheng L, Zhou B, Inose H, Wang J, Guo XE, Grosschedl R, Karsenty G: MiR-34s inhibit osteoblast proliferation and differentiation in the mouse by targeting SATB2. J Cell Biol 2012;197:509-521.

19 Song F, Sun H, Wang Y, Yang H, Huang L, Fu D, Gan J, Huang C: Pannexin3 inhibits TNF-alpha-induced inflammatory response by suppressing NF-kappaB signalling pathway in human dental pulp cells. J Cell Mol Med 2017;21:444-455.

20 Tirino V, Paino F, D’Aquino R, Desiderio V, De Rosa A, Papaccio G: Methods for the identification, characterization and banking of human DPSCs: Current strategies and perspectives. Stem Cell Rev 2011;7:608-615.

-21 Sun H, Wu Y, Fu D, Liu Y, Huang C: SIRT6 regulates osteogenic differentiation of rat bone marrow mesenchymal stem cells partially via suppressing the nuclear factor-kappaB signaling pathway. Stem Cells 2014;32:1943-1955.

22 Sengupta PK, Bouchie MP, Kukuruzinska MA: N-glycosylation gene DPAGT1 is a target of the Wnt/betacatenin signaling pathway. J Biol Chem 2010;285:31164-31173.

23 Tetsu 0, McCormick F: Beta-catenin regulates expression of cyclin D1 in colon carcinoma cells. Nature 1999;398:422-426.

24 Jaiswal RK, Jaiswal N, Bruder SP, Mbalaviele G, Marshak DR, Pittenger MF: Adult human mesenchymal stem cell differentiation to the osteogenic or adipogenic lineage is regulated by mitogen-activated protein kinase. J Biol Chem 2000;275:9645-9652.

-25 Ishikawa M, Iwamoto T, Fukumoto S, Yamada Y: Pannexin 3 inhibits proliferation of osteoprogenitor cells by regulating Wnt and p21 signaling. J Biol Chem 2014;289:2839-2851.

26 Scheller EL, Chang J, Wang CY: Wnt/beta-catenin inhibits dental pulp stem cell differentiation. J Dent Res 2008;87:126-130.

-27 Cho HH, Kim YJ, Kim SJ, Kim JH, Bae YC, Ba B, Jung JS: Endogenous Wnt signaling promotes proliferation and suppresses osteogenic differentiation in human adipose derived stromal cells. Tissue Eng 2006;12:111-121.

28 Shan T, Zhou C, Yang R, Yan F, Zhang P, Fu Y, Jiang H: Lithium chloride promotes the odontoblast differentiation of hair follicle neural crest cells by activating Wnt/beta-catenin signaling. Cell Biol Int 2015;39:35-43.

29 Zhang H, Wang J, Deng F, Huang E, Yan Z, Wang Z, Deng Y, Zhang Q, Zhang Z, Ye J, Qiao M, Li R, Wang J, Wei Q, Zhou G, Luu HH, Haydon RC, He TC, Deng F: Canonical Wnt signaling acts synergistically on BMP9induced osteo/odontoblastic differentiation of stem cells of dental apical papilla (SCAPs). Biomaterials 2015;39:145-154. 


\section{Cellular Physiology Cell Physiol Biochem 2017;44:2174-2188 \begin{tabular}{l|l|l} 
and Biochemistry 10.1159/000486023 & $\begin{array}{l}\text { C) } 2017 \text { The Author(s). Published by S. Karger AG, Basel } \\
\text { www.karger.com/cpb }\end{array}$ \\
\hline
\end{tabular}}

30 Li L, Song H, Zhong L, Yang R, Yang XQ Jiang KL, Liu BZ: Lithium chloride promotes apoptosis in human leukemia NB4 cells by inhibiting glycogen synthase kinase-3 beta. Int J Med Sci 2015;12:805-810.

-31 Quarto N, Senarath-Yapa K, Renda A, Longaker MT: TWIST1 silencing enhances in vitro and in vivo osteogenic differentiation of human adipose-derived stem cells by triggering activation of BMP-ERK/FGF signaling and TAZ upregulation. Stem Cells 2015;33:833-847.

-32 Hu N, Feng C, Jiang Y, Miao Q Liu H: Regulative effect of mir-205 on osteogenic differentiation of bone mesenchymal stem cells (BMSCs): Possible role of SATB2/Runx2 and ERK/MAPK pathway. Int J Mol Sci 2015;16:10491-10506.

-33 Fu D, Song F, Sun H, Pei D, Wang Y, Lei J, Huang C: Expression of Pannexin3 in human odontoblast-like cells and its hemichannel function in mediating ATP release. Arch Oral Biol 2015;60:1510-1516.

-34 Lu D, Soleymani S, Madakshire R, Insel PA: ATP released from cardiac fibroblasts via connexin hemichannels activates profibrotic P2Y2 receptors. FASEB J 2012;26:2580-2591.

-35 Jia C, Hegg CC: Neuropeptide Y and extracellular signal-regulated kinase mediate injury-induced neuroregeneration in mouse olfactory epithelium. Mol Cell Neurosci 2012;49:158-170.

-36 May C, Weigl L, Karel A, Hohenegger M: Extracellular ATP activates ERK1/ERK2 via a metabotropic P2Y1 receptor in a $\mathrm{Ca} 2+$ independent manner in differentiated human skeletal muscle cells. Biochem Pharmacol 2006;71:1497-1509.

37 Huang AH, Snyder BR, Cheng PH, Chan AW: Putative dental pulp-derived stem/stromal cells promote proliferation and differentiation of endogenous neural cells in the hippocampus of mice. Stem Cells 2008;26:2654-2663.

-38 Pierdomenico L, Bonsi L, Calvitti M, Rondelli D, Arpinati M, Chirumbolo G, Becchetti E, Marchionni C, Alviano F, Fossati V, Staffolani N, Franchina M, Grossi A, Bagnara GP: Multipotent mesenchymal stem cells with immunosuppressive activity can be easily isolated from dental pulp. Transplantation 2005;80:836842.

39 Zhang J, Lian M, Cao P, Bao G, Xu G, Sun Y, Wang L, Chen J, Wang Y, Feng G, Cui Z: Effects of nerve growth factor and basic fibroblast growth factor promote human dental pulp stem cells to neural differentiation. Neurochem Res 2017;42:1015-1025.

40 Sakai K, Yamamoto A, Matsubara K, Nakamura S, Naruse M, Yamagata M, Sakamoto K, Tauchi R, Wakao N, Imagama S, Hibi H, Kadomatsu K, Ishiguro N, Ueda M: Human dental pulp-derived stem cells promote locomotor recovery after complete transection of the rat spinal cord by multiple neuro-regenerative mechanisms. J Clin Invest 2012;122:80-90.

41 Yuan J, Cui L, Zhang WJ, Liu W, Cao Y: Repair of canine mandibular bone defects with bone marrow stromal cells and porous beta-tricalcium phosphate. Biomaterials 2007;28:1005-1013.

42 Yasui T, Mabuchi Y, Toriumi H, Ebine T, Niibe K, Houlihan DD, Morikawa S, Onizawa K, Kawana H, Akazawa C, Suzuki N, Nakagawa T, Okano H, Matsuzaki Y: Purified human dental pulp stem cells promote osteogenic regeneration. J Dent Res 2016;95:206-214. 